\title{
Predictors of Outcome and Severity in Adult Filipino Patients with Febrile Neutropenia
}

\author{
Marc Gregory Y. Yu, Ralph Elvi M. Villalobos, \\ Ma. Jasmin Marinela C. Juan-Bartolome, and Regina P. Berba \\ Department of Medicine, Philippine General Hospital, Taft Avenue, Ermita, 1000 Manila, Philippines \\ Correspondence should be addressed to Marc Gregory Y. Yu; marcgreggy@yahoo.com
}

Received 4 June 2015; Accepted 26 August 2015

Academic Editor: Helen A. Papadaki

Copyright (c) 2015 Marc Gregory Y. Yu et al. This is an open access article distributed under the Creative Commons Attribution License, which permits unrestricted use, distribution, and reproduction in any medium, provided the original work is properly cited.

\begin{abstract}
Aim. The study aimed to describe the profile of Filipino febrile neutropenia patients and to determine parameters associated with severe outcomes. Methods. This is a retrospective study of Filipino febrile neutropenia patients admitted to the Philippine General Hospital. Patients were described in terms of clinical presentation and stratified according to the presence or absence of severe outcomes. Prognostic factors were then identified using regression analysis. Results. 115 febrile episodes in 102 patients were identified. Regression analysis yielded prolonged fever $>7$ days prior to admission (OR 2.43; 95\% CI, 0.77-7.74), isolation of a pathogen on cultures (OR 2.69; 95\% CI, 1.04-6.98), and nadir absolute neutrophil count (ANC) < 100 during admission (OR 1.96 ; $95 \%$ CI, 0.75-5.12) as significant predictors of poor outcome. Factors that significantly correlated with better outcome were granulocyte colony-stimulating factor (G-CSF) use (OR 0.31; 95\% CI, 0.11-0.85) and completeness of antibiotic therapy (OR 0.26; 95\% CI, 0.10-0.67). Conclusion. Prolonged fever $>7$ days prior to admission, positive pathogen on cultures, and nadir ANC $<$ 100 during admission predicted severe outcomes, whereas G-CSF use and complete antibiotic therapy were associated with better outcomes. These prognostic variables might be useful in identifying patients that need more intensive treatment and monitoring.
\end{abstract}

\section{Introduction}

Febrile neutropenia refers to the presentation of fever in a neutropenic patient, commonly with an uncontrolled neoplasm of the bone marrow, or in a patient undergoing cytotoxic treatment [1]. Around $50 \%$ of patients with solid tumors and $80 \%$ of those with hematologic malignancies will develop concomitant fever and neutropenia [2]; despite advances in diagnostics and therapy, these patients still face a mortality rate of 5-21.5\% [3-5]. This is partly explained by the fact that neutropenic patients who develop fever have a $60 \%$ chance of being infected. Infections arise from defects caused by the underlying disease, those induced by cytotoxic drugs, and those associated with invasive procedures $[6,7]$. With newer, more potent agents and dose-dense chemotherapy schedules, patients are faced with more severe and prolonged degrees of neutropenia leading to more complications and higher healthcare costs [8].

Gram negative organisms traditionally predominated as the most common causative pathogens in patients with febrile neutropenia $[9,10]$, although there is a rising incidence of Gram positive organisms among Western patients $[11,12]$. In the Philippines, a retrospective study showed Gram negative bacilli (51.5\%) as the most frequently isolated pathogen [3]; in another study involving pediatric patients with malignancy and febrile neutropenia, the most common organisms were Streptococcus viridans, Gram negative bacilli, Staphylococcus epidermidis, Candida sp., and Salmonella sp. [13].

The standard management of patients with febrile neutropenia includes cultures, hospitalization and close observation, and intravenous broad-spectrum antibiotics [14]. However, these patients comprise a heterogeneous group and possess different risks of developing severe infections and complications [15]. Models such as those developed by Talcott et al. [16] and the Multinational Association of Supportive Care in Cancer (MASCC) attempted to aid practitioners in classifying patients into low- and high-risk groups [17-19]. Using these models, poor prognostic variables identified in Western studies included a MASCC score $<21$, an Eastern Cooperative Oncology Group (ECOG) performance status 
score $\geq 2$, chronic bronchitis and heart failure, a monocyte count $<200 \mathrm{~mm}^{3}$, and stress hyperglycemia, among others [20]. In Korea, prognostic indicators included hypotension, previous and invasive fungal infection, recovery from neutropenia, median days to fever, pneumonia, and total febrile days [21, 22].

There is presently no such study in the Philippines. Being a third-world country with limited health resources, the study aims to provide Filipino data on prognostic factors associated with adverse outcomes and mortality and thereby recognize patients that need more intensive treatment and monitoring.

\section{Materials and Methods}

This retrospective study involved adult febrile neutropenia patients, regardless of cause, admitted to the Philippine General Hospital from January 2010 to October 2014. The inclusion criteria consisted of patients $>19$ years old with a suspected or documented risk factor for febrile neutropenia (hematologic malignancy, bone marrow failure state, or solidorgan tumor after myelosuppressive chemotherapy) who developed fever coexistent with or during the neutropenic episode; patients with existing severe infection prior to the onset of neutropenia were excluded. Patients were stratified into the "complicated group" if they developed severe outcomes, defined by any of the following: hypotension (systolic blood pressure $<90 \mathrm{mmHg}$ and/or diastolic blood pressure $<60 \mathrm{mmHg}$ ), respiratory failure (arterial oxygen pressure < $60 \mathrm{mmHg}$ on room air or need for mechanical ventilation), congestive heart failure, uncontrolled arrhythmia, hepatic or renal failure requiring treatment, severe bleeding requiring transfusion, altered sensorium, intensive care unit admission, and death; and they were stratified into the "noncomplicated group" if they did not manifest any severe outcome. Patients who left prior to recommended discharge were assumed to have developed severe outcomes and were categorized under the complicated group.

Clinical, laboratory, and microbiologic data were expressed as frequencies and percentages. Stepwise logistic regression with backward selection strategy was employed on specific variables; the significance of the main effects of the different independent variables on severe outcomes was determined by univariate analysis to establish the strength of association of each independent variable and outcome variable. Univariate test of any variable resulting in a $p$ value $\leq 0.25$ was considered a candidate for the multivariable model. Since some of the variables did not reach significance level $p$ value $\leq 0.25$ in the univariate analysis, a model that included significant variables was constructed. The variables included in the model were then subjected to multivariate analysis.

\section{Results}

3.1. Patient Characteristics. 115 febrile episodes in 102 neutropenic patients were documented. Of these, 58 patients $(50.4 \%)$ were classified under the complicated group and 57 (49.6\%) fell under the noncomplicated group. There was no significant difference in the mean age and sex ratio of the patients between both groups. The overall mortality rate was $19.1 \%$.

Almost half of the sample population had leukemia ( $n=56,48.7 \%)$ as the primary underlying disease, followed by solid-organ tumors ( $n=27,23.45 \%)$. In addition, 21 patients $(18.26 \%)$ did not have a primary hematologic disorder or malignancy as the underlying disease; these included systemic lupus erythematosus (SLE), liver cirrhosis, HIV/AIDS, and drug-induced agranulocytosis. Majority of patients $(n=84,73.04 \%)$ had no comorbidities. In those with comorbidities, cardiovascular disease $(n=21,18.26 \%)$ had the highest frequency.

More patients in the complicated group did not receive treatment and/or had relapse of their underlying disease $(n=$ $26,44.83 \%)$. This nontreatment or relapse status significantly correlated with poor outcomes in the univariate analysis (OR 2.28; 95\% CI, 1.04-4.98; $p=0.040)$. Similarly, prolonged duration of fever $>7$ days prior to admission $(n=16$, $27.6 \%)$, nonrecovery from neutropenia $(n=41,70.7 \%)$, and prolonged duration of neutropenia $>7$ days during admission ( $n=31,53.4 \%)$ were also seen more in the complicated group. However, only the last two variables (OR 2.17; 95\% CI, 1.01-4.68; $p=0.048$; OR 3.24; 95\% CI, 1.16-9.01; $p=$ 0.024 , resp.) were significantly associated with poor outcomes in the univariate analysis. In contrast, more patients in the noncomplicated group received G-CSF ( $n=23,40.3 \%)$ but this did not reach statistical significance in the univariate analysis. The baseline characteristics of the study patients are summarized in Table 1 while the results of the univariate analysis for clinical variables are shown in Table 4 .

3.2. Laboratory Characteristics. More subjects in the complicated group were observed to have ANC counts $<100$ on admission ( $n=19,32.8 \%$ ) as well as nadir ANC counts $<100$ during the entire admission $(n=36,62.1 \%)$. Likewise, more patients in this group had hemoglobin levels $\leq 80 \mathrm{~g} / \mathrm{L}$, platelet counts $\leq 50,000 / \mu \mathrm{L}$, peak BUN $>20 \mathrm{mg} / \mathrm{dL}$, peak creatinine $>177 \mu \mathrm{mol} / \mathrm{L}$, nadir bicarbonate $\leq 21 \mathrm{mmol} / \mathrm{L}$, nadir albumin $\leq 30 \mathrm{~g} / \mathrm{L}$, and peak AST and ALT levels > $40 \mathrm{IU} / \mathrm{L}$. Among these factors, however, only severe thrombocytopenia showed significant prognostic correlation with poor outcomes in the univariate analysis (OR 3.45; 95\% CI, $1.52-7.84 ; p=0.003)$. The laboratory parameters of the study patients are summarized in Table 2 while the results of the univariate analysis are included in Table 4.

3.3. Microbiologic Characteristics. Of the 115 febrile episodes included in the study, $79(68.7 \%)$ were clinically defined infections (CDI), 32 (27.83\%) were microbiologically defined infections (MDI), and four (3.48\%) had fever of unknown origin (FUO). A greater number of patients in the complicated group had MDI ( $n=20,34.5 \%)$. The most common site of infection was the respiratory tract $(n=58,50.43 \%)$ in both groups, followed by the genitourinary tract $(n=13$, $22.4 \%)$ in the complicated group and the oral cavity $(n=15$, $26.3 \%)$ in the noncomplicated group. The overall bacteremia 
TABLE 1: Baseline clinical characteristics of febrile neutropenia cases.

\begin{tabular}{|c|c|c|}
\hline \multirow[b]{2}{*}{ Clinical parameter } & \multicolumn{2}{|c|}{ Outcome frequency (\%) } \\
\hline & $\begin{array}{l}\text { Complicated } \\
\text { group } \\
n=58(50.4)\end{array}$ & $\begin{array}{c}\text { Noncomplicated } \\
\text { group } \\
n=57(49.6)\end{array}$ \\
\hline \multicolumn{3}{|l|}{ Age } \\
\hline Mean (SD) & 41.24 (15.99) & $40(11.89)$ \\
\hline Median & 40.5 & 42 \\
\hline Range & $19-71$ & $19-61$ \\
\hline \multicolumn{3}{|l|}{ Sex } \\
\hline Male & $23(39.7)$ & $24(42.1)$ \\
\hline Female & $35(60.3)$ & $33(57.9)$ \\
\hline \multicolumn{3}{|l|}{ Primary underlying disease } \\
\hline Leukemia & $29(50)$ & $27(47.4)$ \\
\hline Lymphoma (all sites) & $1(1.7)$ & $1(1.8)$ \\
\hline Solid-organ tumor & $9(15.5)$ & $18(31.6)$ \\
\hline Bone marrow failure state & $6(10.3)$ & $3(5.2)$ \\
\hline Others & $13(22.4)$ & $8(14.0)$ \\
\hline \multicolumn{3}{|l|}{ Comorbid } \\
\hline None & $41(70.7)$ & $43(7.5)$ \\
\hline Cardiovascular disease & $8(13.8)$ & $13(22.8)$ \\
\hline Pulmonary disease & $1(1.7)$ & 0 \\
\hline Liver disease & 0 & $1(1.8)$ \\
\hline Renal disease & $3(5.2)$ & 0 \\
\hline Diabetes mellitus & $2(3.4)$ & 0 \\
\hline Others & $3(5.2)$ & 0 \\
\hline \multicolumn{3}{|l|}{ Outcome } \\
\hline Discharged improved & $32(60.3)$ & $57(100.0)$ \\
\hline Expired & $22(37.9)$ & 0 \\
\hline Left against advice & $4(6.9)$ & 0 \\
\hline \multicolumn{3}{|l|}{ Status of treatment } \\
\hline Treated/on treatment & $32(55.2)$ & $40(70.2)$ \\
\hline Remission & 0 & $2(3.5)$ \\
\hline Relapse & $3(5.2)$ & $3(5.3)$ \\
\hline Not on treatment & $23(39.7)$ & $12(21)$ \\
\hline \multicolumn{3}{|l|}{ Type of treatment } \\
\hline Chemotherapy & $26(44.8)$ & $28(49.1)$ \\
\hline Combination therapy & $6(10.3)$ & $17(29.8)$ \\
\hline None & $26(44.8)$ & $12(21.1)$ \\
\hline \multicolumn{3}{|l|}{ G-CSF use } \\
\hline Yes & $16(27.6)$ & $23(40.3)$ \\
\hline No & $42(72.4)$ & $34(59.7)$ \\
\hline \multicolumn{3}{|l|}{$\begin{array}{l}\text { Duration of fever prior to } \\
\text { admission }\end{array}$} \\
\hline$\leq 7$ days & $42(72.4)$ & $51(89.5)$ \\
\hline$>7$ days & $16(27.6)$ & $6(10.5)$ \\
\hline \multicolumn{3}{|l|}{$\begin{array}{l}\text { Duration of neutropenia } \\
\text { during admission }\end{array}$} \\
\hline$\leq 7$ days & $27(46.6)$ & $35(61.4)$ \\
\hline$>7$ days & $31(53.4)$ & $22(39.6)$ \\
\hline \multicolumn{3}{|l|}{ Recovery from neutropenia } \\
\hline Yes & $17(29.3)$ & $27(47.4)$ \\
\hline No & $41(70.7)$ & $30(52.6)$ \\
\hline
\end{tabular}

rate was $13.04 \%$, but this did not show statistical significance in the univariate analysis.
TABLE 2: Laboratory parameters of febrile neutropenia cases.

\begin{tabular}{|c|c|c|}
\hline \multirow{2}{*}{ Laboratory parameter } & \multicolumn{2}{|c|}{ Outcome frequency (\%) } \\
\hline & $\begin{array}{l}\text { Complicated } \\
\text { group }\end{array}$ & $\begin{array}{c}\text { Noncomplicated } \\
\text { group }\end{array}$ \\
\hline \multicolumn{3}{|c|}{ ANC on admission $\left(\mathrm{mm}^{-3}\right)$} \\
\hline$\leq 100$ & $19(32.8)$ & $13(22.8)$ \\
\hline$>100$ & $39(67.2)$ & $44(77.2)$ \\
\hline \multicolumn{3}{|c|}{$\begin{array}{l}\text { Nadir ANC during admission } \\
\left(\mathrm{mm}^{-3}\right)\end{array}$} \\
\hline$\leq 100$ & $36(62.1)$ & $26(45.6)$ \\
\hline$>100$ & $22(37.9)$ & $31(54.4)$ \\
\hline \multicolumn{3}{|l|}{ Nadir hemoglobin (g/L) } \\
\hline$>80$ & $18(31)$ & $23(40.4)$ \\
\hline$\leq 80$ & $40(69)$ & $34(59.6)$ \\
\hline \multicolumn{3}{|c|}{ Nadir platelet count $\left(\mu \mathrm{L}^{-3}\right)$} \\
\hline$\leq 50,000$ & $46(79.3)$ & $30(52.6)$ \\
\hline$>50,000$ & $12(20.7)$ & $27(47.4)$ \\
\hline \multicolumn{3}{|c|}{ Peak serum BUN (mg/dL) } \\
\hline$>20$ & $3(5.2)$ & 0 \\
\hline$\leq 20$ & $35(60.3)$ & $29(50.9)$ \\
\hline No data & $20(34.5)$ & $28(49.1)$ \\
\hline \multicolumn{3}{|l|}{$\begin{array}{l}\text { Peak serum creatinine } \\
(\mu \mathrm{mol} / \mathrm{L})\end{array}$} \\
\hline$>177$ & $9(15.5)$ & $2(3.5)$ \\
\hline$\leq 177$ & $45(81.8)$ & $47(82.5)$ \\
\hline No data & $4(6.9)$ & $8(14)$ \\
\hline \multicolumn{3}{|c|}{$\begin{array}{l}\text { Nadir serum bicarbonate } \\
(\mathrm{mmol} / \mathrm{L})\end{array}$} \\
\hline$\leq 21$ & $15(25.9)$ & 0 \\
\hline$>21$ & $5(8.6)$ & $5(8.8)$ \\
\hline No data & $38(65.5)$ & $52(91.2)$ \\
\hline \multicolumn{3}{|c|}{ Nadir serum albumin $(\mathrm{g} / \mathrm{L})$} \\
\hline$\leq 30$ & $33(56.9)$ & $20(35.1)$ \\
\hline$>30$ & $10(17.2)$ & $6(10.5)$ \\
\hline No data & $15(25.9)$ & $31(54.4)$ \\
\hline \multicolumn{3}{|l|}{ Peak serum AST (IU/L) } \\
\hline$>40$ & $21(36.2)$ & $17(29.8)$ \\
\hline$\leq 40$ & $17(29.3)$ & $17(29.8)$ \\
\hline No data & $20(34.5)$ & $23(40.4)$ \\
\hline \multicolumn{3}{|l|}{ Peak serum ALT (IU/L) } \\
\hline$>40$ & $22(37.9)$ & $18(31.6)$ \\
\hline$\leq 40$ & $18(31)$ & $16(28.1)$ \\
\hline No data & $18(31)$ & $23(40.3)$ \\
\hline
\end{tabular}

Pseudomonas aeruginosa ( $n=9,7.83 \%$ ) was the most commonly isolated organism, followed by Escherichia coli ( $n=7,6.09 \%)$. As a whole, Gram negative bacteria comprised the predominant isolate in the complicated group. Isolation of a pathogen in cultures, however, was not significantly associated with poor outcomes in the univariate analysis. In contrast, complete antibiotic therapy significantly predicted 
TABle 3: Microbiologic profiles of febrile neutropenia cases.

\begin{tabular}{|c|c|c|}
\hline \multirow[b]{2}{*}{ Microbiologic parameter } & \multicolumn{2}{|c|}{ Outcome frequency (\%) } \\
\hline & $\begin{array}{l}\text { Complicated } \\
\text { group }\end{array}$ & $\begin{array}{l}\text { Noncomplicated } \\
\text { group }\end{array}$ \\
\hline \multicolumn{3}{|l|}{ Infection type } \\
\hline MDI & $20(34.5)$ & $12(21.1)$ \\
\hline CDI & $36(62.1)$ & $43(75.4)$ \\
\hline FUO & $2(3.4)$ & $2(3.5)$ \\
\hline \multicolumn{3}{|l|}{ Site of infection } \\
\hline Oral cavity & $2(3.4)$ & $15(26.3)$ \\
\hline Respiratory tract & $33(56.9)$ & $25(43.9)$ \\
\hline GI tract/intra-abdominal & $4(6.9)$ & $2(3.5)$ \\
\hline Genitourinary tract & $13(22.4)$ & $6(10.5)$ \\
\hline Skin and soft tissue & $4(6.9)$ & $6(10.5)$ \\
\hline Unknown & $1(1.7)$ & 0 \\
\hline Others & $1(1.7)$ & $3(5.6)$ \\
\hline \multicolumn{3}{|l|}{ Bacteremia } \\
\hline Yes & $7(12.1)$ & $8(14)$ \\
\hline No & $51(87.9)$ & $49(86)$ \\
\hline \multicolumn{3}{|l|}{ Isolated organism } \\
\hline $\begin{array}{l}\text { Gram positive bacteria, } \\
\text { non-MDRO }\end{array}$ & $3(12)$ & 0 \\
\hline $\begin{array}{l}\text { Gram positive bacteria, } \\
\text { MDRO }\end{array}$ & $3(12)$ & $1(6.7)$ \\
\hline $\begin{array}{l}\text { Gram negative bacteria, } \\
\text { non-MDRO }\end{array}$ & $8(32)$ & $4(26.7)$ \\
\hline $\begin{array}{l}\text { Gram negative bacteria, } \\
\text { MDRO }\end{array}$ & $7(28)$ & $4(26.7)$ \\
\hline Fungus & $4(16)$ & $4(26.7)$ \\
\hline $\mathrm{TB}$ & 0 & $2(13.3)$ \\
\hline \multicolumn{3}{|l|}{ Antibiotic use } \\
\hline Complete & $21(36.2)$ & $39(68.4)$ \\
\hline Incomplete & $37(64.8)$ & $18(31.2)$ \\
\hline
\end{tabular}

${ }^{*}$ MDRO: multi-drug-resistant organism.

better outcomes in the univariate analysis (OR 0.26 ; $95 \%$ CI, 0.12-0.57; $p=0.001$ ) with Piperacillin-Tazobactam being the most commonly administered antibiotic $(n=57,49.57 \%)$.

The microbiologic profiles of the study patients are summarized in Table 3 while the results of the univariate analysis are displayed in Table 4 .

3.4. Multivariate Analysis. Significant variables in the univariate analysis resulting in a $p$ value $\leq 0.25$ were considered candidates for the multivariable model. Since some variables did not reach significance level $p$ value $\leq 0.25$ in the univariate analysis, a model that included significant variables was constructed. Results of the multivariate analysis showed prolonged fever $>7$ days prior to admission (OR 2.43; 95\% CI, $0.77-7.74$ ) being associated with a significant risk for poorer outcomes. In the same manner, isolation of a known pathogen on cultures (OR 2.69; 95\% CI, 1.04-6.98) and profound ANC $<100$ during admission (OR 1.96; 95\% CI, 0.75-5.12) were
TABle 4: Prognostic factors related to severe outcomes based on univariate analysis.

\begin{tabular}{|c|c|c|}
\hline Variable & OR (95\% CI) & $\begin{array}{c}p \\
\text { value }\end{array}$ \\
\hline Age & $1.00(0.98-1.03)$ & 0.635 \\
\hline \multicolumn{3}{|l|}{ Sex } \\
\hline \multicolumn{3}{|l|}{ Male } \\
\hline Female & $1.11(0.53-2.33)$ & 0.789 \\
\hline \multicolumn{3}{|c|}{ Primary underlying disease } \\
\hline $\begin{array}{l}\text { Hematologic disease } \\
\text { Others }\end{array}$ & \multicolumn{2}{|c|}{ Others } \\
\hline \multicolumn{3}{|l|}{ Status of treatment } \\
\hline \multicolumn{3}{|l|}{ Treated } \\
\hline Not treated & $2.28(1.04-4.98)$ & 0.040 \\
\hline \multicolumn{3}{|l|}{ G-CSF use } \\
\hline Yes & $0.56(0.26-1.23)$ & 0.150 \\
\hline \multicolumn{3}{|l|}{ No } \\
\hline \multicolumn{3}{|l|}{ Comorbid } \\
\hline Yes & $1.27(0.56-2.91)$ & 0.566 \\
\hline \multicolumn{3}{|l|}{ No } \\
\hline \multicolumn{3}{|l|}{$\begin{array}{l}\text { Duration of fever prior to } \\
\text { admission }\end{array}$} \\
\hline \multicolumn{3}{|l|}{$\leq 7$ days } \\
\hline$>7$ days & $3.24(1.16-9.01)$ & 0.024 \\
\hline \multicolumn{3}{|c|}{ ANC on admission $\left(\mathrm{mm}^{-3}\right)$} \\
\hline$\leq 100$ & $1.65(0.72-3.77)$ & 0.236 \\
\hline \multicolumn{3}{|c|}{$>100$} \\
\hline \multicolumn{3}{|c|}{$\begin{array}{l}\text { Nadir ANC during admission } \\
\left(\mathrm{mm}^{-3}\right)\end{array}$} \\
\hline$\leq 100$ & $1.95(0.93-4.10)$ & 0.078 \\
\hline \multicolumn{3}{|c|}{$>100$} \\
\hline \multicolumn{3}{|c|}{$\begin{array}{l}\text { Duration of neutropenia during } \\
\text { admission }\end{array}$} \\
\hline \multicolumn{3}{|c|}{$\leq 7$ days } \\
\hline$>7$ days & $1.83(0.87-3.84)$ & 0.112 \\
\hline \multicolumn{3}{|c|}{ Recovery from neutropenia } \\
\hline \multicolumn{3}{|c|}{ Yes } \\
\hline No & $2.17(1.01-4.68)$ & 0.048 \\
\hline \multicolumn{3}{|l|}{ Nadir hemoglobin (g/L) } \\
\hline$\leq 80$ & $1.50(0.70-3.24)$ & 0.298 \\
\hline \multicolumn{3}{|c|}{$>80$} \\
\hline \multicolumn{3}{|c|}{ Nadir platelet count $\left(\mu \mathrm{L}^{-3}\right)$} \\
\hline$\leq 50,000$ & $3.45(1.52-7.84)$ & 0.003 \\
\hline$>50,000$ & & \\
\hline Peak serum creatinine ( & & \\
\hline$\leq 177$ & & \\
\hline$>177$ & $4.70(0.96-22.95)$ & 0.056 \\
\hline Bacteremia & & \\
\hline Yes & $0.84(0.28-2.49)$ & 0.754 \\
\hline No & & \\
\hline Isolated organism & & \\
\hline Unknown & & \\
\hline Known & $2.12(0.97-4.65)$ & 0.061 \\
\hline Antibiotic use & & \\
\hline Complete & $0.26(0.12-0.57)$ & 0.001 \\
\hline Incomplete & & \\
\hline
\end{tabular}


TABle 5: Prognostic factors related to severe outcomes based on multivariate analysis.

\begin{tabular}{lcc}
\hline Variable & OR $(95 \%$ CI $)$ & $\begin{array}{c}\text { Standard } \\
\text { error }\end{array}$ \\
\hline $\begin{array}{l}\text { G-CSF use } \\
\quad \text { Yes }\end{array}$ & $0.31(0.11-0.85)$ & 0.16 \\
$\quad$ No & & \\
Duration of fever prior to admission & \\
$\quad \leq 7$ days & $2.44(0.77-7.74)$ & 1.44 \\
$\quad>7$ days & & \\
$\begin{array}{l}\text { Nadir ANC during admission } \\
\left.\text { (mm }{ }^{-3}\right)\end{array}$ & \\
$\quad \leq 100$ & $1.96(0.75-5.11)$ & 0.96 \\
$\quad>100$ & & \\
Isolated organism & & \\
$\quad$ Unknown & & \\
$\quad$ Known & & \\
Antibiotic use & & \\
$\quad$ Complete & & \\
$\quad$ Incomplete & $0.26(0.11-0.67)$ & \\
\hline
\end{tabular}

also found to be significant predictors of poor outcome. The factors that significantly correlated with better outcome, on the other hand, were G-CSF use (OR 0.31; 95\% CI, 0.11-0.85) and completeness of antibiotic therapy (OR $0.26 ; 95 \% \mathrm{CI}$, $0.10-0.67)$. The results of the multivariate analysis are shown in Table 5.

\section{Discussion}

This is the first Philippine study dealing with prognostic variables in patients with febrile neutropenia. Our results generally show that febrile neutropenia confers a significant morbidity and mortality rate: 58 patients (50.4\%) developed severe outcomes, with 22 (19.1\%) of these eventually succumbing. This is consistent with the $5-21.5 \%$ mortality rate documented in the literature [3-5]. Leukemia was found to be the most common primary underlying disease, also consistent with the findings of earlier studies [3]. The nature of hematologic malignancies, plus the intensity of myelosuppressive treatment, predisposes these patients to a more rapid development of neutropenia and consequent infection, as compared to patients with solid tumors [19, 22].

Of the different clinical variables examined, prolonged fever $>7$ days prior to admission and G-CSF use both showed prognostic importance in the multivariate analysis. In contrast, our results did not consider the presence of comorbidities as significant indicators, as opposed to other studies [2022]. This can be explained by the relatively small number of study patients with comorbid diseases. In terms of laboratory findings, multivariate analysis yielded a nadir ANC $<100$ during admission as an indicator of adverse outcome. Since neutropenia is the main defect in host defense after chemotherapy, variables associated with neutropenia are closely related to infection susceptibility and are therefore likely to affect prognosis [21]. However, many of the study patients had incomplete workup (lacking, e.g., albumin, bicarbonate, and liver enzyme levels) and no data on levels of promising prognostic markers (procalcitonin, erythrocyte sedimentation rate, and C-reactive protein) $[23,24]$, thereby precluding the use of these variables for logistic regression analysis.

The predominance of the respiratory tract as the most common site of infection among study patients, as well as the isolation of Pseudomonas and E. coli as the most frequently implicated organisms, conformed with the results of previous studies $[3,21,22]$. In particular, the predominance of Gram negative bacteria in the complicated group affirms the reemergence of these pathogens as a result of more intensive chemotherapy regimens and the decreased use of quinolone prophylaxis [25].

A unique microbiologic profile observed in the study was the presence of tuberculosis in two cases, which was not observed in the literature. This can be explained by the unusually high prevalence of the disease in the country. Furthermore, no viral infection was documented in the study. As the main defect in host immunity after chemotherapy is in the innate rather than adaptive immunity, viral infections following chemotherapy do not seem to be common. The rarity of fungal infections, too, can be explained by the difficulty in confirming fungal infections as the condition of febrile neutropenic patients seldom permits invasive diagnostic procedures [21].

The study was limited by a small sample size and involvement of only one tertiary medical center and hence may have led to underestimation or overestimation of projections. It was also conducted in a resource-limited setting and was thereby constrained by the unavailability of full workup and ideal treatment in many patients, precluding these from further analyses. Finally, the data might not have been completely independent because several febrile episodes were assessed in the same patients. Thus, the presence of confounding factors, despite the use of an appropriate statistical model, cannot be fully excluded in multivariate analysis. This is a common difficulty encountered in retrospective studies [22].

\section{Conclusion and Recommendations}

Adult Filipino febrile neutropenia patients with prolonged fever $>7$ days prior to admission, known pathogen on cultures, and nadir ANC $<100$ during admission were at significant risk of developing worse outcomes, whereas those with G-CSF use and complete antibiotic therapy were significantly associated with better outcomes. These variables might help identify patients with an increased risk of developing complications, thereby needing more intensive treatment and monitoring. The completeness of antibiotic therapy cannot be overemphasized and could lead to improved drug procurement policies for indigent patients. We recommend, however, bigger studies to further validate and strengthen our study findings.

\section{Conflict of Interests}

There was no conflict of interests. 


\section{References}

[1] E. Braunwald, A. S. Fauci, D. L. Kasper et al., Harrison's Principles of Internal Medicine, McGraw-Hill, 18th edition, 2008.

[2] J. Crawford, D. C. Dale, and G. H. Lyman, "Chemotherapyinduced neutropenia," Cancer, vol. 100, no. 2, pp. 228-237, 2004.

[3] K. Billote, M. Mendoza, and H. Baylon, "Infections in febrile neutropenia and possible prognostic factors associated with mortality," Philippine Journal of Microbiology and Infectious Diseases, vol. 26, no. 2, pp. 55-59, 1997.

[4] N. M. Kuderer, D. C. Dale, J. Crawford, L. E. Cosler, and G. H. Lyman, "Mortality, morbidity, and cost associated with febrile neutropenia in adult cancer patients," Cancer, vol. 106, no. 10, pp. 2258-2266, 2006.

[5] G. H. Lyman, S. L. Michels, M. W. Reynolds, R. Barron, K. S. Tomic, and J. Yu, "Risk of mortality in patients with cancer who experience febrile neutropenia," Cancer, vol. 116, no. 23, pp. 5555-5563, 2010.

[6] H. Giamarellou, "Empiric therapy for infections in the febrile, neutropenic, compromised host," Medical Clinics of North America, vol. 79, no. 3, pp. 559-580, 1995.

[7] A. E. Brown, "Neutropenia, fever, and infection," The American Journal of Medicine, vol. 76, no. 3, pp. 421-428, 1984.

[8] N. Lathia, N. Mittmann, C. DeAngelis et al., "Evaluation of direct medical costs of hospitalization for febrile neutropenia," Cancer, vol. 116, no. 3, pp. 742-748, 2010.

[9] N. Hiransuthikul, T. Tantawichien, P. Suwangool, and T. Nuchprayoon, "Febrile neutropenia in Chulalongkorn Hospital during 1994-1995," Chulalongkorn Medical Journal, vol. 40, pp. 781-799, 1996.

[10] N. Voravud and V. Sriuranpong, "Febrile neutropenia after chemotherapy in patients with non-hematologic malignancies," Chulalongkorn Medical Journal, vol. 47, pp. 151-161, 2003.

[11] R. Feld, "Bloodstream infections in cancer patients with febrile neutropenia," International Journal of Antimicrobial Agents, vol. 32, supplement 1, pp. S30-S33, 2008.

[12] H. Wisplinghoff, H. Seifert, R. P. Wenzel, and M. B. Edmond, "Current trends in the epidemiology of nosocomial bloodstream infections in patients with hematological malignancies and solid neoplasms in hospitals in the United States," Clinical Infectious Diseases, vol. 36, no. 9, pp. 1103-1110, 2003.

[13] A. Isais-Agdeppa and L. Bravo, "A five-year retrospective study on the common microbial isolates and sensitivity pattern on blood culture of pediatric cancer patients admitted at the Philippine General Hospital for febrile neutropenia," Philippine Journal of Microbiology and Infectious Diseases, vol. 9, no. 2, 2005.

[14] A. G. Freifeld, E. J. Bow, K. A. Sepkowitz et al., "Clinical practice guideline for the use of antimicrobial agents in neutropenic patients with cancer: 2010 update by the infectious diseases society of America," Clinical Infectious Diseases, vol. 52, no. 4, pp. e56-e93, 2011.

[15] M. Paesmans, "Risk factors assessment in fabrile neutropenia," International Journal of Antimicrobial Agents, vol. 16, no. 2, pp. 107-111, 2000.

[16] J. A. Talcott, R. D. Siegel, R. Finberg, and L. Goldman, "Risk assessment in cancer patients with fever and neutropenia: a prospective, two-center validation of a prediction rule," Journal of Clinical Oncology, vol. 10, no. 2, pp. 316-322, 1992.

[17] J. Klastersky, M. Paesmans, E. B. Rubenstein et al., “The multinational association for supportive care in cancer risk index: a multinational scoring system for identifying low-risk febrile neutropenic cancer patients," Journal of Clinical Oncology, vol. 18, no. 16, pp. 3038-3051, 2000.

[18] A. Uys, B. L. Rapoport, and R. Anderson, "Febrile neutropenia: a prospective study to validate the Multinational Association of Supportive Care of Cancer (MASCC) risk-index score," Supportive Care in Cancer, vol. 12, no. 8, pp. 555-560, 2004.

[19] S. Ahn, Y.-S. Lee, Y.-H. Chun et al., "Predictive factors of poor prognosis in cancer patients with chemotherapy-induced febrile neutropenia," Supportive Care in Cancer, vol. 19, no. 8, pp. 1151-1158, 2011.

[20] A. Carmona-Bayonas, J. Gómez, E. González-Billalabeitia et al., "Prognostic evaluation of febrile neutropenia in apparently stable adult cancer patients," British Journal of Cancer, vol. 105, no. 5, pp. 612-617, 2011.

[21] J.-H. Yoo, S. M. Choi, D.-G. Lee et al., "Prognostic factors influencing infection-related mortality in patients with acute leukemia in Korea," Journal of Korean Medical Science, vol. 20, no. 1, pp. 31-35, 2005.

[22] Y. Park, D. S. Kim, S. J. Park et al., "The suggestion of a risk stratification system for febrile neutropenia in patients with hematologic disease," Leukemia Research, vol. 34, no. 3, pp. 294300, 2010.

[23] L. Persson, P. Engervall, A. Magnuson et al., "Use of inflammatory markers for early detection of bacteraemia in patients with febrile neutropenia," Scandinavian Journal of Infectious Diseases, vol. 36, no. 5, pp. 365-371, 2004.

[24] M. Ortega, M. Rovira, M. Almela, J. P. de la Bellacasa, E. Carreras, and J. Mensa, "Measurement of C-reative protein in adults with febrile neutropenia after hematopoietic cell transplantation," Bone Marrow Transplantation, vol. 33, no. 7, pp. 741-744, 2004.

[25] S. Gençer, T. Salepçi, and S. Özer, "Evaluation of infectious etiology and prognostic risk factors of febrile episodes in neutropenic cancer patients," Journal of Infection, vol. 47, no. 1, pp. 65-72, 2003. 


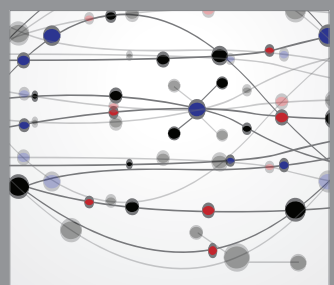

The Scientific World Journal
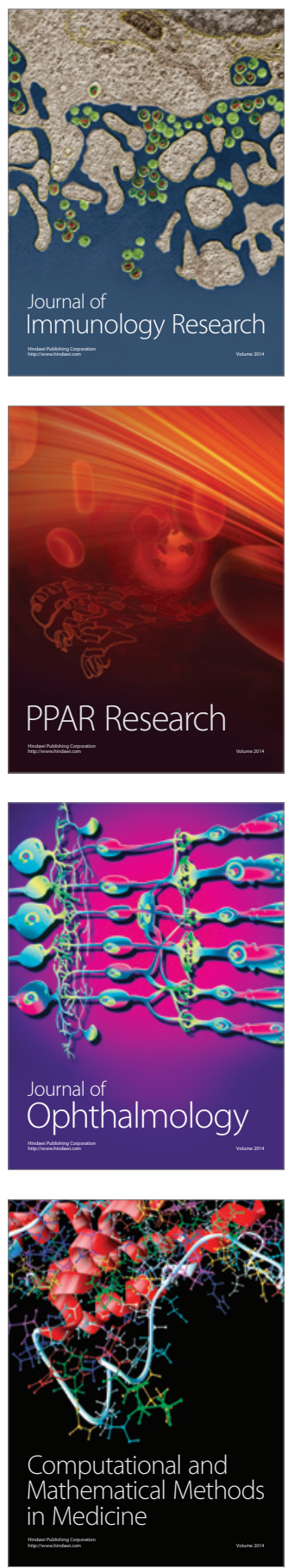

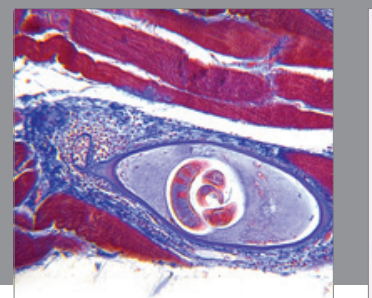

Gastroenterology

Research and Practice
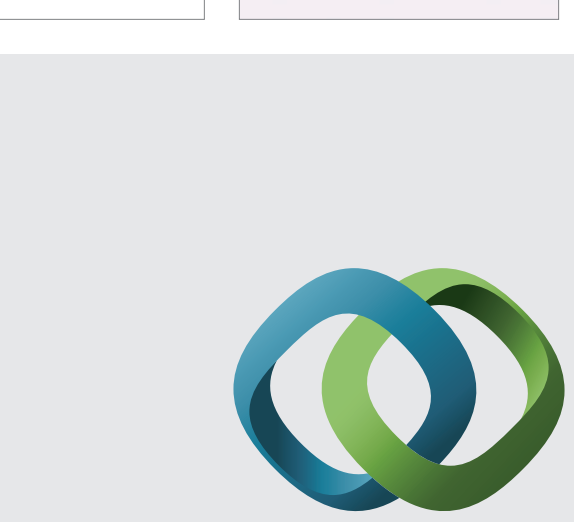

\section{Hindawi}

Submit your manuscripts at

http://www.hindawi.com
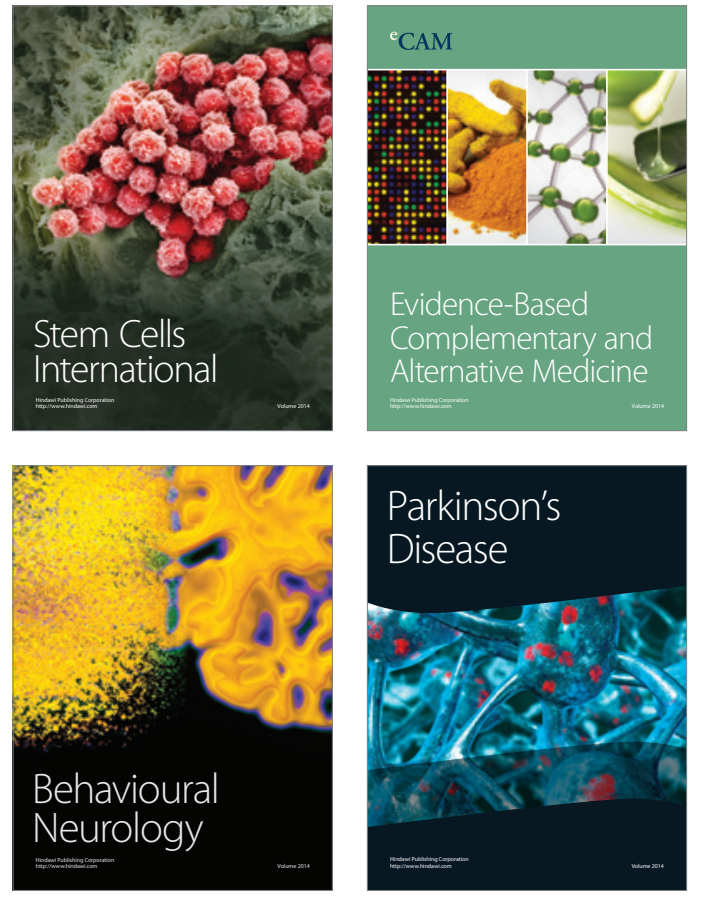
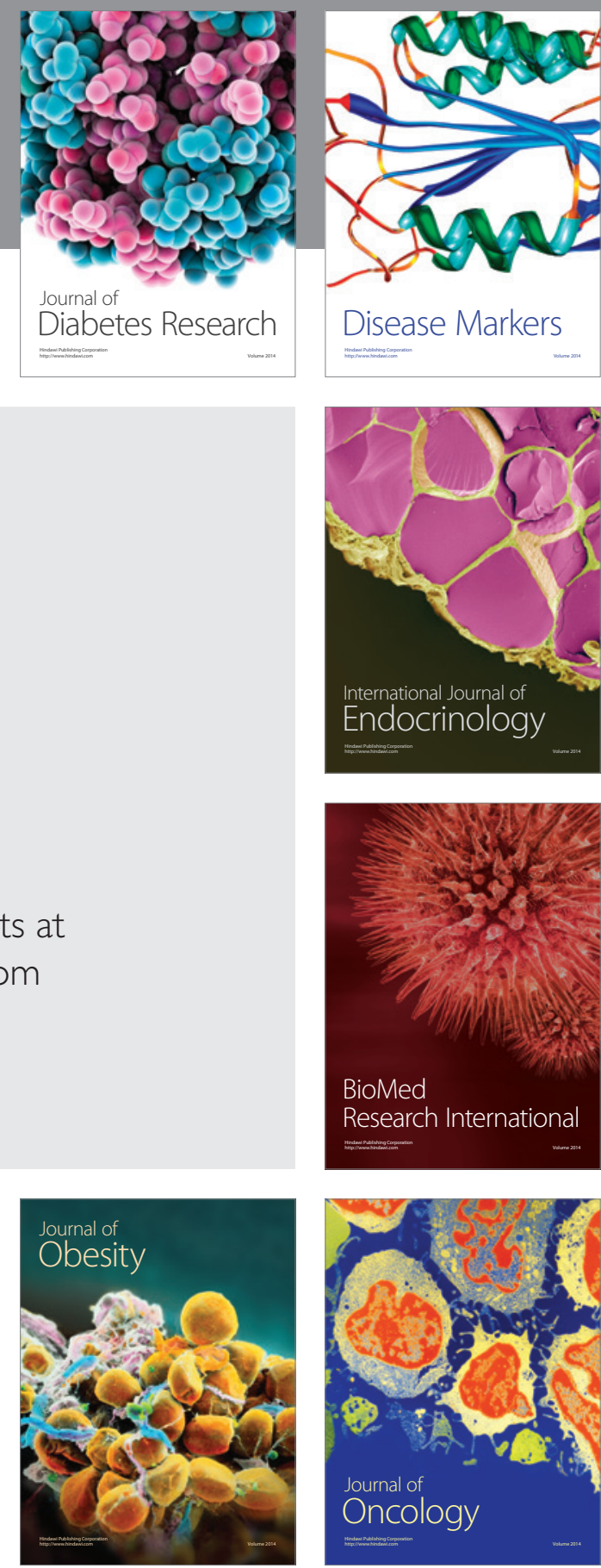

Disease Markers
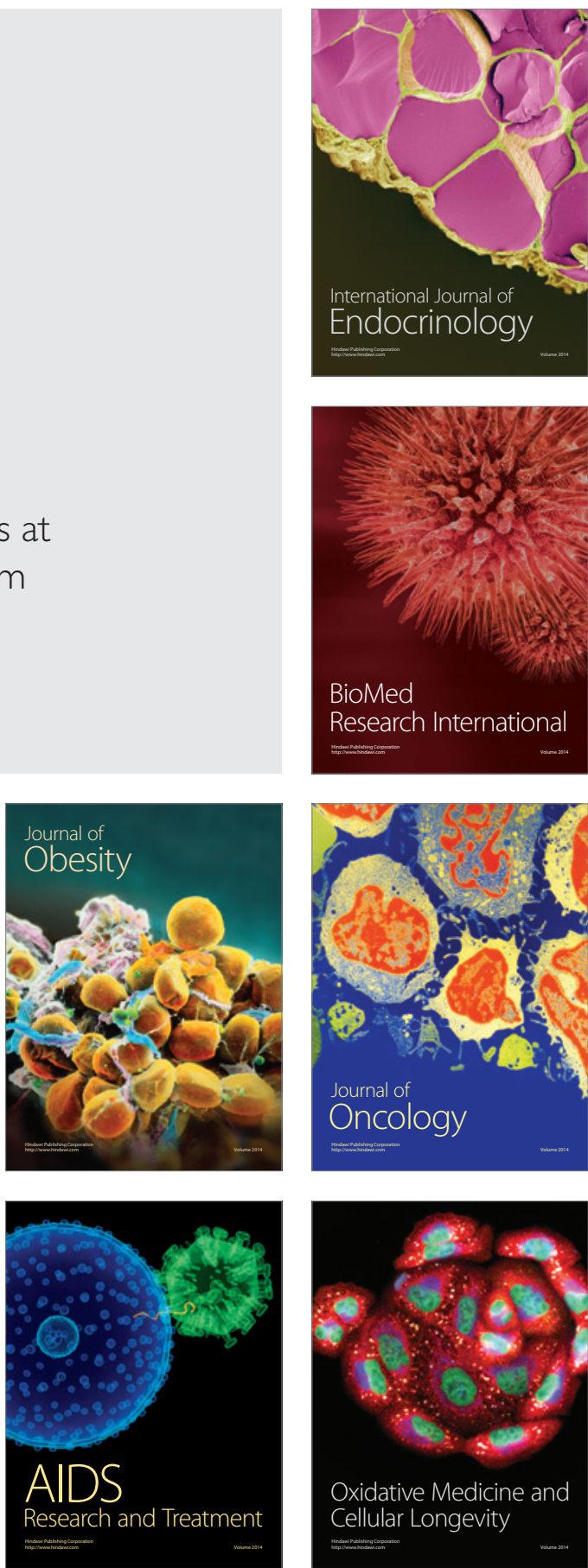